\title{
Influence of Synthesis Parameters on the Structure, Pore Morphology and Bioactivity of a New Mesoporous Glass
}

\author{
Nouha Letaief ${ }^{1,2}$, Anita Lucas-Girot ${ }^{1}$, Hassane Oudadesse ${ }^{1}$, Rachida Dorbez-Sridi ${ }^{2}$ \\ ${ }^{1}$ Université de Rennes 1, ISCR, UMR CNRS 6226, Rennes, France \\ ${ }^{2}$ Université de Monastir, Faculté des Sciences, Monastir, Tunisie \\ Email: anita.lucas@univ-rennes1.fr
}

Received March 2014

\begin{abstract}
The main objective of the present work was to investigate the effect of surfactant type and synthesis temperature on the structure, porosity and the bioactivity of $92 \mathrm{~S} 6\left(92 \% \mathrm{SiO}_{2}, 6 \% \mathrm{CaO}\right.$, and $2 \%$ $\mathrm{P}_{2} \mathrm{O}_{5} \mathrm{~mol} \%$ ) mesoporous sol-gel glasses. The aim was to provide a basis for controlling the bioactive behavior of the different $92 \mathrm{~S} 6$ samples used for tissue regeneration and for biomedical engineering in order to obtain sufficient performances by controlling the porosity of the glass. In this paper, a series of mesoporous bioactive glasses were synthesized using three different surfactants $\left(\mathrm{C}_{10} \mathrm{H}_{20} \mathrm{BrN}, \mathrm{C}_{19} \mathrm{H}_{42} \mathrm{BrN}, \mathrm{C}_{22} \mathrm{H}_{48} \mathrm{BrN}\right)$ at different aging temperatures $\left(20^{\circ} \mathrm{C}, 40^{\circ} \mathrm{C}\right.$ and $\left.60^{\circ} \mathrm{C}\right)$. The surfactant was removed by calcination, which was carried out by increasing the temperature to $650^{\circ} \mathrm{C}$ for $6 \mathrm{~h}$. A comparison among these synthesized glasses was conducted and the research emphasis was placed on the synthesis temperature and the surfactant type dependence on the textural properties and particularly porosity that were ultimately responsible for glass bioactivity.
\end{abstract}

\section{Keywords}

Mesoporous Glass; Sol-Gel; Bioactive Glass; Hydroxyapatite

\section{Introduction}

Various kinds of bioactive materials like hydroxyapatite, bioglasses, bioglass-ceramics and calcium phosphate ceramics have attracted a strong interest of research over the last decades and have shown significant potential in biomedical research field. These glasses could facilitate bone integration of the implant [1], they are intended to replace bone through a bone defect area in the human skeleton [2] [3]. The bioactive behavior of those glasses, which is identified as capability of bone bonding, is attributed to the formation of an apatite-like layer, whose composition and structure are equivalent to the mineral phase in bone [4].

In the last couple of decades, there has been some interest in porous glasses in applications where bone ingrowth is needed or as coatings in applications such as implants [5] [6], where a good bone-implant interface is required [7] [8]. Porous biomaterials have been produced by several techniques such as the use of polymeric 
sponge, foaming processes and techniques using organic additives such as $n$-hexadecyltrimethylammonium bromide CTAB [7].

The porous structure is induced by the condensation of silica around supramolecular surfactant aggregates acting as a structure-directing agent, and the pores are formed upon removal of the surfactant from the matrix by calcination [9]. The resulting amorphous material is biocompatible and degradable in aqueous solution as well as in simulated body fluid (SBF) [9]. It's well known that a bioactive material is one that elicits a specific biological response at the interface of the material and allows the attachment to the tissue, such as soft tissue and bone [2]. When bioactive materials are implanted in human body, their interface can be transformed to calcium phosphate phase (apatite phase) through of series of surface reactions including dissolution-precipitation and ion exchange denoted as "bioactive process" [3]. For bioactive glasses, variables such as chemical composition, structure, surface morphology, and synthesis conditions, such as temperature, $\mathrm{pH}$, and reactant ratios, are influent parameters on the bioactivity [6] [10]-[15]. All these factors must be taken into account when applying this synthesis route to biomaterials, as the bioactive process is a surface process and the response of the living tissue will be ruled by the surface characteristics of the implant [16] [17].

The objective of this paper is to report the preparation of mesoporous glasses in the system $\mathrm{SiO}_{2}-\mathrm{CaO}-\mathrm{P}_{2} \mathrm{O}_{5}$ through sol-gel route. In order to analyze changes in 92S6 textural properties, synthesized at different aging temperatures and using different length of CTAB chain, and in order to estimate the values of parameters describing the properties of pore structure, nitrogen adsorption isotherms were used. In vitro bioactivity of glasses was investigated to analyze its feasibility as biomaterial.

\section{Experimental Procedure}

\subsection{Preparation of Mesoporous Bioactive Glass Samples (92S6)}

Tetraethyl orthosilicate (TEOS), Triethyl phosphate (TEP) and calcium carbonate $\mathrm{CaCO}_{3}$ were used, respectively, as a silica source, source of phosphorous, and a source of calcium. The surfactant $n$-hexadecyltrimethylammonium bromide CTAB was used as a structure-directing agent.

Samples were prepared by the solgel process. The synthesis was carried out according to the modified Stöber's method described for synthesis of monodisperse silica spheres MCM-41 [18]. In the first step, the solution was prepared as follows: $2.5 \mathrm{~g}$ of commercial surfactant $\left(\mathrm{C}_{10} \mathrm{H}_{20} \mathrm{BrN}, \mathrm{C}_{19} \mathrm{H}_{42} \mathrm{BrN}, \mathrm{C}_{22} \mathrm{H}_{48} \mathrm{BrN}\right)$ was dissolved in $50 \mathrm{~mL}$ of deionized water and mixed with $75 \mathrm{~mL}$ of absolute ethanol, at room temperature. $3.6 \mathrm{~g}$ of TEOS is further added to this solution and kept under strong stirring for one hour. Under stirring, $0.16 \mathrm{~g}$ of TEP and an acidic $\mathrm{CaCO}_{3}$ solution were added. In the second step, the mixture was stirred for 24 hours at $20^{\circ} \mathrm{C}$. Finally $18.53 \mathrm{~mL}$ of aqueous ammonia solution (25\% wt, Fluka, France) was added to this clear solution and stirred for $15 \mathrm{~min}$. At the end of the addition of aqueous ammonia solution, the gel formation immediately began. The white precipitate was isolated by filtration and washed several times with water and ethanol until neutral pH was reached. In order to study the effect of the temperature, we used the sample prepared with $\mathrm{C}_{19} \mathrm{H}_{42} \mathrm{BrN}$ and we chose to vary aging temperature $\left(20^{\circ} \mathrm{C}, 40^{\circ} \mathrm{C}\right.$ and $\left.60^{\circ} \mathrm{C}\right)$. Samples were dried at $90^{\circ} \mathrm{C}$ overnight. The surfactant was removed by calcination, treating the dried gel at $650^{\circ} \mathrm{C}$ for $6 \mathrm{~h}$. The resulting bioactive glass was crushed and sieved to select grain size less than $63 \mu \mathrm{m}$. Samples were then characterized.

Materials are named as 92S6-C10, 92S6-C19 and 92S6-C22 according to the number of carbons of the surfactant and 92S6-T20, 92S6-T40 and 92S6-T60 according to aging temperature.

\subsection{Samples Characterization}

Scanning electron microscopy (SEM) was performed on a JEOL-JSM-6301F instrument. Specific surface area and pore size distribution of the materials were determined by nitrogen $\mathrm{N}_{2}$ adsorption-desorption using a Micromeritics ASAP-2010. The pore size distribution was determined using the BJH method (desorption) [19].

\subsection{In Vitro Bioactivity Test}

Samples were immersed in SBF solution at $37^{\circ} \mathrm{C} \pm 0.5^{\circ} \mathrm{C}$, for $7,15,21$ and 30 days. This solution has ion concentrations and $\mathrm{pH}$ nearly equal to those of human blood plasma [20]. The glass specimen before soaking in SBF is termed as zero days' specimen. A solid to liquid ratio of $1 \mathrm{mg} / 2 \mathrm{ml}$ was maintained for all immersions, and the SBF solutions were not renewed during the experiments. The samples were removed from the incubator, 
rinsed with deionized water and left to dry at ambient temperature over night.

\section{Results and Discussion}

\subsection{Effect of CTAB Carbon Chain Length}

Nitrogen isotherms of calcined 92S6-C10, 92S6-C19 and 92S6-C22 are shown in Figure 1. In all cases, the isotherms were of type IV and exhibited hysteresis loops of H3 type for 92S6-C10 and 92S6-C19 glasses, and H4 type for 92S6-C22, according the IUPAC classification, which is associated with the presence of mesopores. Table 1 summarizes the different pore sizes, specific areas and pore volumes in samples. Synthesized glasses show specific surface area $\left(\mathrm{S}_{\mathrm{BET}}\right)$ in the range of 88 to $248 \mathrm{~m}^{2} \cdot \mathrm{g}^{-1}$. It shows that the use of different surfactants has a significant influence on glass specific area. On the other hand, a decrease of pore volume (Vp) is observed, the value is declined from $0.28 \mathrm{~cm}^{3} / \mathrm{g}$ to $0.13 \mathrm{~cm}^{3} / \mathrm{g}$ with increasing the number of surfactant carbons. The $\mathrm{N}_{2}$ adsorption experiments revealed that these materials have an average pore size varying from $2.6 \mathrm{~nm}$ to $8.24 \mathrm{~nm}$. It seems that the length of carbon chains plays an important role in the formation of the mesoporous structure. The large pore diameter is related to relatively long chain of carbon of surfactant. These results are associated to the mechanism of formation of these glasses. CATB surfactant is formed by a hydrophilic head facing the outside of the micelle and by the hydrophobic carbon chains facing the center. The increase of the number of carbons results in an increase of pore diameter in glasses prepared with different surfactants [21].

\subsection{Effect of Aging-Temperature}

To investigate the effect of the aging-temperature on the changes of glasses pore structure, textural properties were studied by the analysis of nitrogen adsorption-desorption isotherms. The nitrogen adsorption-desorption of the glasses synthesized at various temperatures are depicted in Figure 2. The curves are identifiable as Type IV with H3 hysteresis loops for 92S6-T20 glass, H4 hysteresis loops for 92S6-T40 glass and H2 hysteresis loops for 92S6-T60 glass. Type IV isotherm is typical of mesoporous materials. The results of the glasses textural properties are shown in Table 2. All synthesized glasses show high specific surface area $\left(\mathrm{S}_{\mathrm{BET}}\right)$ in the range of 224 to $559 \mathrm{~m}^{2} \cdot \mathrm{g}^{-1}$. The increase of specific surface area can be related to stronger micelle-silica interactions,

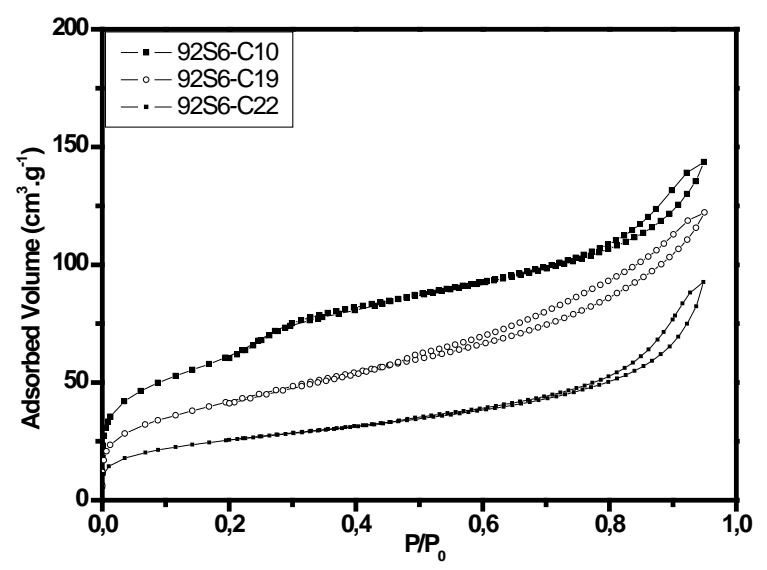

Figure 1. $\mathrm{N}_{2}$ adsorption/desorption isotherms of 92S6-C10, 92S6-C19 and 92S6-C22.

Table 1. Textural properties of sol-gel glasses synthesized with different length of the carbon chain template.

\begin{tabular}{cccc}
\hline Samples & $\mathrm{S}_{\mathrm{BET}}\left(\mathrm{m}^{2} / \mathrm{g}\right)$ & $\mathrm{Vp}\left(\mathrm{cm}^{3} / \mathrm{g}\right)$ & $\mathrm{D}_{\mathrm{p}}(\mathrm{nm})$ \\
\hline 92S6-C10 & 248 & 0.28 & 2.6 \\
92S6-C19 & 224 & 0.16 & 4.85 \\
92S6-C22 & 88 & 0.13 & 8.24 \\
\hline
\end{tabular}




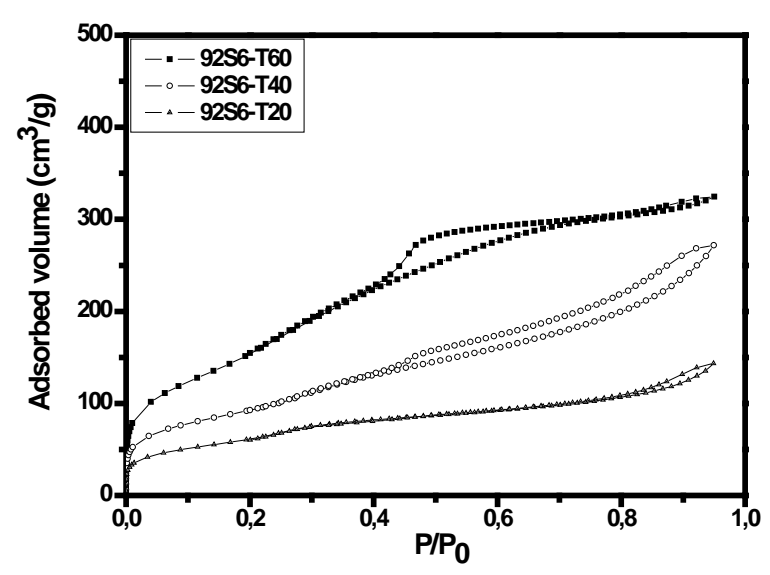

Figure 2. $\mathrm{N}_{2}$ adsorption/desorption isotherms of 92S6-T20, 92S6-T40 and 92S6-T60.

Table 2. Textural properties of sol-gel glasses synthesized at various temperatures.

\begin{tabular}{cccc}
\hline Samples & $\mathrm{S}_{\mathrm{BET}}\left(\mathrm{m}^{2} / \mathrm{g}\right)$ & $\mathrm{Vp}\left(\mathrm{cm}^{3} / \mathrm{g}\right)$ & $\mathrm{D}_{\mathrm{p}}(\mathrm{nm})$ \\
\hline $92 \mathrm{~S} 6-20$ & 224 & 0.16 & 4.85 \\
$92 \mathrm{~S} 6-40$ & 332 & 0.34 & 4.38 \\
$92 \mathrm{~S} 6-60$ & 559 & 0.37 & 3.10 \\
\hline
\end{tabular}

which favors the incorporation of the surfactants, increasing the number of the mesopores, and consequently, increasing $\mathrm{S}_{\mathrm{BET}}$ [22].

Some differences were observed in the adsorption isotherms as a function of the aging temperature. The positions of the adsorption branches for 92S6 glasses shifted toward higher pressures as the synthesis temperature increased, indicating no presence of microporosity.

With the increase of the synthesis temperature, the capillary condensation step is shifted to higher relative pressures (Figure 2), corresponding to the formation of larger cavities, which can explain the increase of the pore volume.

\subsection{In Vitro Bioactivity of the $92 \mathrm{~S} 6$ in SBF}

The in vitro physico-chemical analyses are useful to explain the observations on ex vivo specimens [23]. We presented here ICP-OES results obtained for glasses synthesized using three different surfactants, and SEM results obtained for glasses synthesized at different aging temperature.

\subsubsection{Chemical Reactivity Investigation Using ICP-OES}

Figure 3 shows the evolutions of calcium and phosphorous ionic concentrations with the soaking time in SBF for 92S6-C10, 92S6-C19 and 92S6-C22. As it can be observed, variation of Ca and P concentration in SBF followed the same tendency for the three glasses. However, these evolutions were different for each glass. For 92S6-C22, Ca and P concentrations reached a maximum after 15 days of soaking in SBF and gradually decreased up to 30 days, while for 92S6-C19 and 92S6-C10 Ca and P concentrations, show a an increase the first 7 days of soaking, followed by a decrease in concentration. This is due to the small surface area of 92S6-C22 compared to the surface area of the two other glasses, as reported before. This leads to faster formation of hydroxyapatite layer at the surface of 92S6-C19 and 92S6-C10 than at the 92S6-C22 surface.

These observations highlight ionic exchanges between the surface material and the medium (ionic release from the glass followed by ionic uptake by the glass surface), which lead to the formation of the apatite layer. According to Hench, these changes in ionic concentrations demonstrated the dissolution/precipitation process: [24] a hydrated silica layer formed at the surface of bioactive glass prior to the deposition of HA, and these 


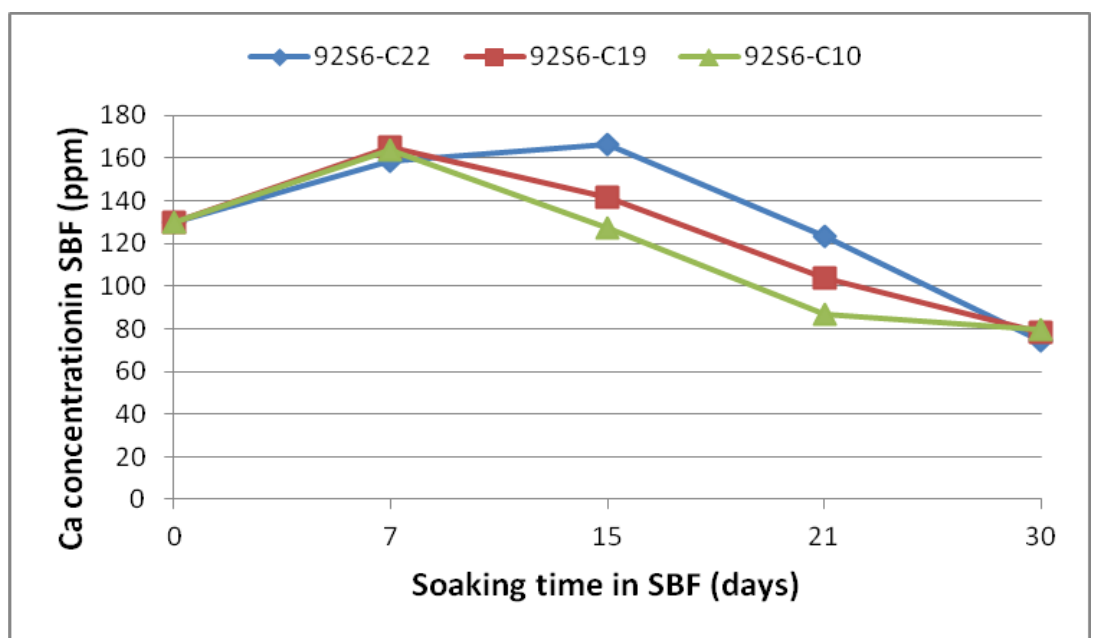

(a)

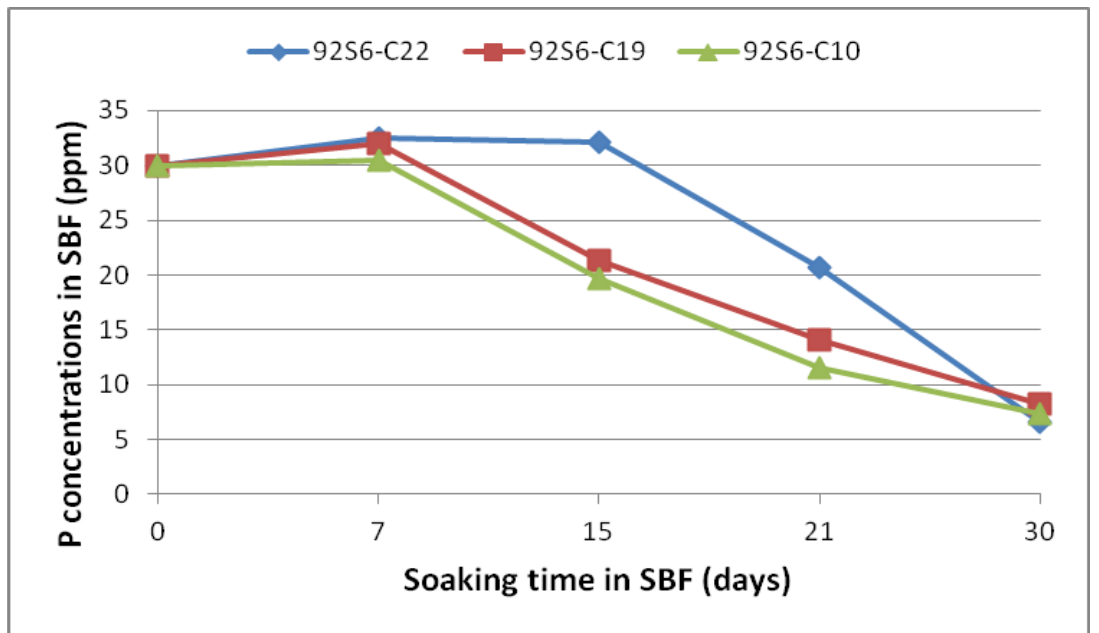

(b)

Figure 3. Evolution of $\mathrm{Ca}$ (a) and $\mathrm{P}$ (b) concentrations in SBF, versus soaking time for 92S6-C10, 92S6-C19 and 92S6-C22 glasses.

silanol groups (Si-OH) could be specific sites for apatite nucleation. The variations of Ca concentration can be explained by $\mathrm{Ca}^{2+}$ ions release from the glass network, and the consecutive apatite layer formation that causes the Ca concentration decrease in SBF.

92S6-C10 and 92S6-C19 glasses have been shown to nucleate HAP more rapidly than 92S6-C22 glass. This was mainly attributed to the large surface area afforded by the glasses synthesized with $\mathrm{C}_{10} \mathrm{TAB}$ and $\mathrm{C}_{19} \mathrm{TAB}$ surfactants.

\subsubsection{Scanning Electron Microscopy}

Figure 4(a), 4(c), 4(e) show the micrographs of the 92S6-T20, 92S6-T40 and 92S6-T60 samples, respectively, before soaking in SBF. The morphological structure results in the formation of spherical mesoporous particles exhibiting a dense and smooth appearance (high coalescence degree) whatever the synthesis temperature; but the size of the individual particles increases with the synthesis temperature. At $20^{\circ} \mathrm{C}$, the size of the individual particles tends to be smaller with a size of $30-50 \mathrm{~nm}$. The particles of the material synthesized at $40^{\circ} \mathrm{C}$ are made of agglomerates of spheroidal nanoparticles with size of $50-150 \mathrm{~nm}$. When increasing the synthesis temperature to $60^{\circ} \mathrm{C}$, the size of these spheroidal particles is larger $(100-300 \mathrm{~nm})$ than those obtained for 92S6-T20 and 92S6-T40. This is related to the increase of the nucleation rate (higher supersaturation and polycondensation rate). 


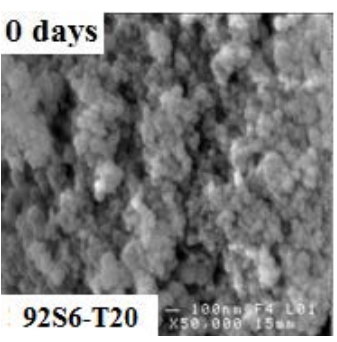

(a)

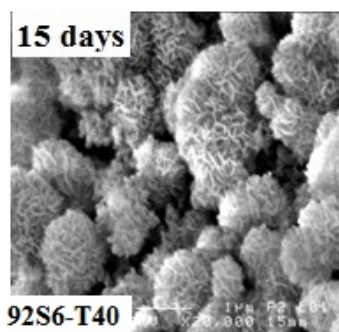

(d)

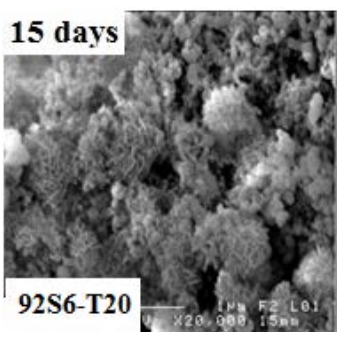

(b)

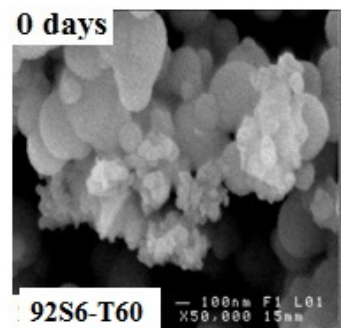

(e)

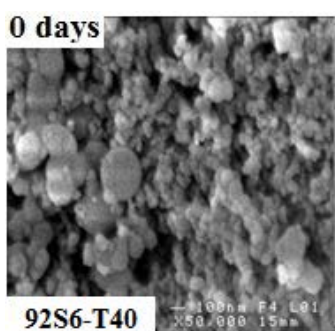

(c)

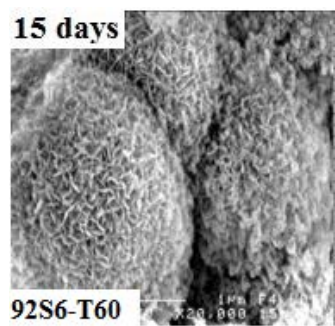

(f)

Figure 4. SEM micrographs of bioactive glasses (a), (b) 92S6-T20, (c), (d) 92S6-T40 and (e), (f) 92S6-T60 surfaces before $(\times 50000)$ and after soaking for 2 weeks in SBF solution $(\times 20000)$.

The formation of hydroxyapatite deposition on the glasses surfaces after immersion in SBF was also observed by SEM. Figure 4(b), 4(d), 4(e) show the surface morphology of glasses specimen incubated in SBF for 2 weeks. The surface morphology changed as the synthesis temperature was increased. 92S6-T20 surface (Figure 4(b)) shows the formation of submicron apatite grains. With increasing aging temperature to $40^{\circ} \mathrm{C}$, apatite grains (Figure 4(d)) grows like spherical balls with an average diameter of $\sim 1 \mu \mathrm{m}$ size. The density of the micro spherical particles of 92S6-T60 glass was approximately 3 times higher than those of 92S6-T40 glass (Figure 4(e)). Furthermore, the surface shows clusters with cauliflower like morphology covering the entire surface.

\section{Conclusions}

The solid surface reaction is of particular importance in the field of biomaterials, since they will be in contact with an aqueous medium and in presence of cells and proteins.

Factors such as the length of carbons chain of the surfactant and the temperature of the reaction mixture determine, as it has been shown here, the particle morphology and the porous characteristics of the final mesoporous glasses.

\section{References}

[1] Xia, W. and Chang, J. (2006) Well-Ordered Mesoporous Bioactive Glasses (MBG): A Promising Bioactive Drug Delivery System. Journal of Controlled Release, 110, 522-530. http://dx.doi.org/10.1016/j.jconrel.2005.11.002

[2] Elbatal, H.A., Azooz, M.A., Khalil, E.M.A., Soltan Monem, A. and Hamdy, Y.M. (2003) Characterization of Some Bioglass-Ceramics. Materials Chemistry and Physics, 80, 599-609. http://dx.doi.org/10.1016/S0254-0584(03)00082-8

[3] Stoch, A., Jastrzebski, W., Brozek, A., Trybalska, B., Cichocinska, M. and Szarawara, E. (1999) FTIR Monitoring of the Growth of the Carbonate Containing Apatite Layers from Simulated and Natural Body Fluids. Journal of Molecular Structure, 511-512, 287-294. http://dx.doi.org/10.1016/S0022-2860(99)00170-2

[4] Cannillo, V., Pierli, F., Ronchetti, I., Siligardi, C. and Zaffe, D. (2009) Chemical Durability and Microstructural Analysis of Glasses Soaked in Water and in Biological Fluids. Ceramics International, 35, 2853-2869. http://dx.doi.org/10.1016/j.ceramint.2009.03.029

[5] Nayak, J.P., Kumar, S. and Bera, J. (2010) Sol-Gel Synthesis of Bioglass-Ceramics Using Rice Husk Ash as a Source for Silica and Its Characterization. Journal of Non-Crystalline Solids, 365, 1447-1451. http://dx.doi.org/10.1016/j.jnoncrysol.2010.04.041

[6] Ma, J., Chen, C.Z., Wang, D.G. and Shi, J.Z. (2010) Textural and Structural Studies of Sol-Gel Derived SiO ${ }_{2}-\mathrm{CaO}-$ 
$\mathrm{P}_{2} \mathrm{O}_{5}$-MgO Glasses by Substitution of MgO for CaO. Materials Science and Engineering C, 30, 886-890. http://dx.doi.org/10.1016/j.msec.2010.04.005

[7] Prado da Silva, M.H., Lemos, A.F., Gibson, I.R., Ferreira, J.M.F. and Santos, J.D. (2002) Porous Glass Reinforced Hydroxyapatite Materials Produced with Different Organic Additives. Journal of Non-Crystalline Solids, 304, $286-292$. http://dx.doi.org/10.1016/S0022-3093(02)01036-0

[8] Elgayar, I., Aliev, A. E., Boccaccini, A.R. and Hill, R.G. (2005) Structural Analysis of Bioactive Glasses. Journal of Non-Crystalline Solids, 351, 173-183. http://dx.doi.org/10.1016/j.jnoncrysol.2004.07.067

[9] Andersson, J., Areva, S., Spliethoff, B. and Linden, M. (2005) Sol-Gel Synthesis of a Multifunctional, Hierarchically Porous Silica/Apatite Composite. Biomaterials, 26, 6827. http://dx.doi.org/10.1016/j.biomaterials.2005.05.002

[10] Pei, L., Kurumada, K.-I., Tanigaki, M., Hiro, M. and Susa, K.-J. (2004) Effect of Drying Rate on Mesoporous Silica Morphology Templated from PEO-PPO-PEO Block Copolymer Assemblies. Materials Science, 39, 4045-4047. http://dx.doi.org/10.1023/B:JMSC.0000031492.71835.2b

[11] Yu, C.-Z., Fan J., Tian, B.-Z. and Zhao, D.-Y. (2004) Morphology Development of Mesoporous Materials: A Colloidal Phase Separation Mechanism. Chemistry of Materials, 16, 889. http://dx.doi.org/10.1021/cm035011g

[12] Bao, X.-Y., Zhao, X.-S., Li, X. and Li, J. (2004) Pore Structure Characterization of Large-Pore Periodic Mesoporous Organosilicas Synthesized with Varying SiO2/Template Ratios. Journal of Applied Surface Science, 237, 380-386. http://dx.doi.org/10.1016/j.apsusc.2004.06.072

[13] Bennadja, Y., Beaunier, P., Margolese, D. and Davidson, A. (2001) Fine Tuning of the Interaction between Pluronic Surfactants and Silica Walls in SBA-15 Nanostructured Materials. Microporous and Mesoporous Materials, 44, 147152.

[14] Tang, J.-W.,Yu, C.-Z, Zhou, X.-F., Yan, X.X. and Zhao, D.Y. (2004) The Anion Sequence in the Phase Transformation of Mesostructures Templated by Non-Ionic Block Copolymers. Chemical Communications, 19, 2240. http://dx.doi.org/10.1039/b408100e

[15] Yu, C.-Z., Tian, B.-Z., Fan B., Stucky, G.-D. and Zhao, D.-Y. (2001) Salt Effect in the Synthesis of Mesoporous Silica Templated by Non-Ionic Block Copolymers. Chemical Communications, 24, 2726-2727. http://dx.doi.org/10.1039/b107640j

[16] Hench, L.-L., Splinter, R.-J., Greenlee, T.-K. and Allen, W.-C. (1971) Bonding Mechanisms at the Interface of Ceramic Prosthetic Materials. Journal of Biomedical Materials Research, 2, 117. http://dx.doi.org/10.1002/jbm.820050611

[17] Vallet-Regi, M., Acros, D. and Pererz-Pariente, J. (2000) Evolution of Porosity during in Vitro Hydroxycarbonate Apatite Growth in Sol-Gel Glasses. Journal of Biomedical Materials Research, 51, 23-28. http://dx.doi.org/10.1002/(SICI)1097-4636(200007)51:1<23::AID-JBM4>3.0.CO;2-B

[18] Szegedi, Á., Kónya, Z., Méhn, D., Solymár, E., Pál-Borbély, G., Horváth, Z.E., Biró, L. P. and Kiricsi, I. (2004) Spherical Mesoporous MCM-41 Materials Containing Transition Metals: Synthesis and Characterization. Applied Catalysis A, 272, 257-266. http://dx.doi.org/10.1016/j.apcata.2004.05.057

[19] Zhu, Y., Wu, C., Ramaswamy, Y., Kockrick, E., Simon, P., Kaskel, S. and Zreiqat, H. (2008) Preparation, Characterization and in Vitro Bioactivity of Mesoporous Bioactive Glasses (MBGs) Scaffolds for Bone Tissue Engineering. Microporous and Mesoporous Materials, 112, 494. http://dx.doi.org/10.1016/j.micromeso.2007.10.029

[20] Kokubo, T., Hushitani, H., Sakka, S. and Yamamuro, S.T. (1990) Solutions Able to Reproducein Vivo Surface-Structure Changes in Bioactive Glass-Ceramic A-W3. Journal of Biomedical Materials Research, 24, 721-734. http://dx.doi.org/10.1002/jbm.820240607

[21] Guo, Y., Zhou, Y., Jia, D. and Tang, H. (2009) Fabrication and Characterization of Hydroxycarbonate Apatite with Mesoporous Structure. Microporous and Mesoporous Materials, 118, 480-488. http://dx.doi.org/10.1016/j.micromeso.2008.09.024

[22] Mesa, M., Sierra, L., Lopez, B., Ramirez, A. and Guth, J.-L. (2003) Preparation of Micron-Sized Spherical Particles of Mesoporous Silica from a Triblock Copolymer Surfactant, Usable as a Stationary Phase for Liquid Chromatography. Solid State Sciences, 5, 1303-1308. http://dx.doi.org/10.1016/S1293-2558(03)00185-7

[23] Ducheyne, P. and Qiu, Q. (1999) Bioactive Ceramics: The Effect of Surface Reactivity on Bone Formation and Bone Cell Function. Biomaterials, 20, 2287-2303. http://dx.doi.org/10.1016/S0142-9612(99)00181-7

[24] Mezahi, F.Z., Lucas-Girot, A., Oudadesse, H. and Harabi, A. (2013) Reactivity Kinetics of 52S4 Glass in the Quaternary System $\mathrm{SiO}_{2}-\mathrm{CaO}-\mathrm{Na}_{2} \mathrm{O}-\mathrm{P}_{2} \mathrm{O}_{5}$ : Influence of the Synthesis Process: Melting Versus Sol-Gel. Journal of NonCrystalline Solids, 361, 111-118. http://dx.doi.org/10.1016/j.jnoncrysol.2012.10.013 